\title{
Use of Transmedia Storytelling for Teaching Teenagers
}

\author{
Ana Cristina Munaro', Alboni Marisa Dudeque Pianovski Vieira² \\ ${ }^{1}$ Post Graduate Program in Administration of the Pontifical Catholic University of Paraná, Curitiba, Brazil \\ ${ }^{2}$ Post Graduate Program in Education of the Pontifical Catholic University of Paraná, Curitiba, Brazil \\ Email:ana.munaro@pucpr.edu.br,alboni@alboni.com
}

Received 6 April 2016; accepted 22 May 2016; published 25 May 2016

Copyright (C) 2016 by authors and Scientific Research Publishing Inc.

This work is licensed under the Creative Commons Attribution International License (CC BY).

http://creativecommons.org/licenses/by/4.0/

(c) (i) Open Access

\section{Abstract}

The use of stories combined with communication and information technologies can be a solution to bring together teachers and students in the processes of teaching and learning, with a view to exploring and sharing the content more effectively. In a time of convergence and unprecedented possibilities for protecting learning experiences, the use of creative and information sharing devices is part of the participatory culture, which takes into account the characteristics of the teenage audience, who do not accept one-way teaching that is closed to opportunities for improvement. The study carried out a literature review to verify the effectiveness of using transmedia storytelling in the teaching and learning process. The results showed that many of the studies carried out have been exploratory, and as such, certain mistakes can be seen in the implementation of transmedia storytelling in the classroom, including the frequent use of stories not connected to transmedia communication. The methodology has also been employed to complement teaching based on case studies and problem solving. Even so, the use of transmedia storytelling in education does engage teachers and appears to be effective for learning.

\section{Keywords}

Transmedia Storytelling, Teaching-Learning, Engagement

\section{Introduction}

The teaching-learning process has become a challenge in schools and universities, due in particular to the ubiquity of information and communication technologies that question traditional teaching methods and provide many opportunities for working with active methodologies that allow the learning process to be monitored and evaluated more effectively. In the digital age, educators are faced with difficult problems: a changing landscape 
in the media; a break with traditional ways of teaching; and the rapid development of mobile technologies and its inherent impact in the context of education. However, this new era has also brought unprecedented opportunities for developing learning, and many new ways of designing learning experiences (Rodrigues \& Bidarra, 2014).

These possibilities are linked to the fact that teenagers today, aged between 12 and 19, part of the so-called Generation Z (which comes from "zapping”), are critical, dynamic, demanding, self-taught, they know what they want, and they do not like hierarchy and non-flexible timetables. They have fun playing games and doing sport. The internet is their main source of entertainment, and they have a great affinity for activities such as games, chat rooms, updating their social media accounts with photos/videos, writing on blogs, and downloading music, with many of these activities being carried out simultaneously (Ibope Media, 2015).

Teenagers constitute a segment of society that knows how to deal with technology, efficiently exploring the media and its transfer of information tools. They access the internet, talk on their mobile phones, listen to music, do homework, read magazines, and watch television, all of this almost simultaneously (Tapscott, 2010). They take this behaviour into their schools and workplaces, in a fast-paced and fragmented way, requiring new educational and management practices that channel these behaviors in such a way so as to get the best out of this creative and innovative segment (Ceretta \& Froemming, 2011).

The advent of the participative culture has transformed the way in which teaching is imparted. In this context, students express their opinion using content creation tools, and share them in a network environment. Mobility, the development of smartphones, and the use of augmented reality have introduced a new dimension: the integration of the digital world with the physical one (Rodrigues \& Bidarra, 2014). Emphasizing the scene of transmedia storytelling relates to integrated media experiences, which take place on a variety of platforms. According Fitzgibbon and Wilhelm (1998), advocates of storytelling as a teaching tool claim that there are many advantages to use them.

However, few studies can be found that support the supposed benefits of storytelling. Thus, the aim of this research is to answer the question: how effective is the use of transmedia storytelling in engaging teenage university students in the classroom? The research aims to verify the effectiveness of transmedia storytelling in engaging teenagers in the teaching-learning process. The following specific objectives were adopted: to identify how the transmedia storytelling structure is being implemented in the classroom; to analyze the impact on students of the use of transmedia storytelling in teaching; and to assess the role of student's engagement with the transmedia storytelling structure in the teaching process.

The work is structured in the following manner: the first section is the introduction, followed by the theory section, which introduces the concept of transmedia storytelling, the elements of a story, the academic studies on the methodology of storytelling in the teaching-learning process, and, finally, the student engagement variable when exposed to transmedia storytelling. The third section contains the discussions and analyses of empirical studies addressed in this study, after which we will present the final considerations with the limitations and proposals for future research.

\section{Theoretical Framework}

\subsection{Transmedia Storytelling}

Marsha Kinder coined the term "transmedia" in her book "Playing with Power in Movies, Television and Video Games”, published in 1991 (Kinder, 1991). Years later, Henry Jenkins, then a professor at MIT (Massachusetts Institute of Technology) and now at the University of Southern California, published an article called "transmedia storytelling", which expanded the concepts involved in this form of communication and is today one of the leading references on media research in the world.

Transmedia narrative unfolds across many media platforms, with each new text contributing in a different and valuable way to the whole. It represents a new kind of relationship between the receptors and the convergence of media platforms, requiring not only their participation but also the relationship between the agents. In the ideal form of transmedia storytelling, each medium does what it does best-so that a story can be introduced in a film and be expanded by through television, novels, comics, and so on. Each access to the franchise should be autonomous, so it is not necessary watch the film to enjoy the game, and vice versa. The understanding gained through various media platforms creates a depth of experience that encourages consumption (Jenkins, 2007, 2009). 
This fact reinforces the process designated as participative culture (Jenkins et al., 2009), which emerges as the culture absorbs and responds to the increase in new media technologies that make it possible for people to save, annotate, and highlight media content in new and influential ways. As such, it is necessary to highlight that each medium has its own inherent characteristics, its own systems of representation, and its own strategies for producing and organizing information. This enables participants to learn how to navigate in different and sometimes conflicting manners of representation, thus enabling them to make choices on the best way of expressing their ideas in each context (Kress, 2003).

Transmedia storytelling migrated from the area of communication to the field of education, being adopted as a new teaching method, the concept of which has remained largely the same. For Gosciola and Versuti (2012), transmedia storytelling is basically a big story. What makes it different from big stories is that it is divided into different parts. The most important of these is the main story, which does not tell the whole story because that is where the additional stories complement it. Another feature that makes it even more unique is that each of these stories is conveyed using a different means of communication.

For Rodrigues and Bidarra (2014), storytelling is considered an innate human activity, a central element of human communication and the creation of meaning, which enhances the development of individuals and implies a sense of cultural identity. According to Gambarato (2013), transmedia storytelling concerns a widespread story, engaging the attention of the public: it does not try to offer the same content on different media platforms, but rather a different experience of how the world is constructed, unfolding the content and generating possibilities for the story to evolve with new and relevant content.

Kalogeras (2013a, 2013b) uses this concept of educational transmedia storytelling and entertainment (TmSE), which is defined as the use of popular entertainment stories to create educational components in a certain discipline. It sees anything that helps the public with different learning styles can only be beneficial, a claim that still needs to be researched. However, it seems that having a road map allows students to be more engaged in their work, students prefer a story instead of a book, because it is more engaging and keeps their attention better. For Raybourn (2014), transmedia storytelling is defined as a scalable messaging system that represents the narrative or core of an experience that unfolds through the use of different media platforms, engaging students emotionally in their learning and involving them personally in the story.

According to Raybourn (2014), in transmedia learning the messages communicated by interacting with each medium should reinforce improvements in performance, reflection, and behavioral changes. In this emerging culture, social media can be used for comments and forming transmedia history as it evolves. It is an opportunity to explore history more broadly and allow teaching to take place in different ways to enrich the core experience. According to Sánches (2013), transmedia storytelling revolutionized the traditional concept of the recipient of audiovisual (and, by extension, cultural) content. This transformation in the classical content of the recipient is based on four fundamental changes:

1) While the conventional cultural product is aimed at a priority audience, the transmedia product defines different kinds of audiences to which it is connected through different platforms and content, using a network of users who come together to exchange experiences and extend the content of the main narrative (Jenkins, 2007).

2) The transmedia product promotes interactivity; it requires more involvement from the audience in the world of the story than conventional storytelling.

3) It asks the audience to participate as co-creators.

4) It is based on new business models, such as crowdfunding, where the feeling of community work is exploited.

Jenkins (2007) adds that, among the characteristics of transmedia storytelling is the expansion into multiple platforms, connecting different fragments in a way that provides the user a sense of continuity in the story; the construction of a changing world where the notion of space and time is modified by exploring the narrative with new elements and characters who acquire a life of their own; the subjectivity connected to the secondary stories that highlight new narrative experiences and give the characters new perspectives; the technological devices; and the interconnection of parts with the story as a whole.

For Gosciola (2011), the transmedia process starts with an internal narrative, with defined characters, following multiple plot lines (unfolding the life of each characters) and dividing the plots across different media platforms. In the end the plot lines and media platforms are brought together in an attempt to unify the work and establish consistency. Kalogeras (2013a, 2013b) addresses the concept of a film that unfolds across different forms of media and which may have different parts, such as a book, game, and mobile components, a creative practice 
where the story is at the center of the media platforms: this is transmedia storytelling.

It is noted that the use of stories combined with media resources can be a solution to integrate teachers and students in the teaching-learning process, allowing information to be developed and shared more easily. Blumenthal and Xu (2012) discuss the use of connectors that can potentially connect the experience of the participants: mythology in the context of storytelling (it defines the symbols, cultural conflicts and frameworks, the natural and supernatural rules that the author introduces); the canon (representing the official media elements of a fictional universe); the character (important connector throughout all media types and can be an actor, abstract character, or archetype); and gender (defines and classifies similar elements in all the stories, acting as the skeleton of the story).

Through interaction and participation, the audience consumes and transforms the media content, promoting strategies that allow for collaborative building of knowledge in the network society. By stimulating the migration of audiences across different platforms, transmedia storytelling offers experiences of that world that are unique and exclusive to each type of media, provided that said world is structured in a cohesive and coherent manner (Massarolo \& Mesquita, 2013).

Based on the concept of transmedia storytelling, it is clear that the adoption of information creation and sharing devices is part of the participative culture, in a time of convergence and unprecedented possibilities for designing learning experiences. These factors are considered the characteristics of the teenage audience born in the middle of the media scene and no longer accept one-way teaching and closed attitudes to opportunities for improvement.

\section{The Importance of Storytelling}

Stories are fundamental in all human cultures, "the primary means by which common experiences are structures, shared, and understood" (Jenkins 2009: p. 170); humans have a natural tendency to organize information (Padgett \& Allen, 1997); used as a means of self-expression and as a way to make sense of life (Tomkins, 2009). Even informally in daily conversations, the use of storytelling to communicate ideas and express experiences is clear. Children tell stories to their imaginary friends; adults tell stories of their childhood to their children; stories are told between work colleagues about their employers or clients; stories are told to entertain, educate, clarify, or simply to elicit emotion (Fitzgibbon \& Wilhelm, 1998). Stories offer worlds and experiences where everyone has the option to participate as co-creators, telling and listening to the story (Sánchez, 2013).

For Sánchez (2013), the design of a transmedia project requires the construction of a world, rather than the telling of a story. The team of creators must take into account what the world will be where their stories take place, what the main storylines and platforms will be that fit into the whole to enhance the involvement/experience of viewers/users/players. Jenkins (2009) showed that simply telling the story across different media platforms does not guarantee that it is a transmedia story, which should be combined and integrated, not simply transposed. The essential elements of fiction must be systematically presented through multiple channels to create a unified and coordinated entertainment experience.

For Scolari (2009), it is possible to identify at least four strategies for expanding the story: 1) the creation of interspersed micro-stories that enrich the fictional world, expanding the period of the story; examples of this strategy include comics, online videos, videogames; 2) the creation of parallel stories, whose logic is to create another story that unfolds at the same time as the main story; 3) the creation of peripheral stories that can be considered more or less distant "satellites" of the main story; and 4) the creation of content platforms generated by the users, such as blogs, which should be considered as mechanisms for creating the open code of the story that allows users to enrich the fictional world.

Creating and/or telling a good story is an art. Regardless of the elements in the story, the conflict it presents, its environment, theme, characters, or means through which the communication takes place and how the audience is placed, a story must guide and involve the audience. Referencing cultural elements is one way of stirring the audience's imagination and encouraging their participation during the story. All of these aspects are essential for promoting effective learning.

\subsection{Learning through Transmedia Storytelling}

Advances in information and communication technology and the changes that come with that have added to the challenge in the field of education; and the $\mathrm{Y}$ and $\mathrm{Z}$ generations, born in this time of transformation, are faced with increasingly ineffective learning models that need to be reviewed, changed, or replaced. Due to the partic- 
ular characteristics of this new Z Generation which, for Tapscott (2010), is mainly comprised by the desire for freedom in everything they do, from freedom of choice to freedom of expression, this is a generation that often customizes everything to their liking; researching and searching for information comes naturally to them; they want integrity when deciding where to work; they are the generation of collaboration and relationship; entertainment is the keyword, since they are growing up surrounded by interactive experiences; they want speed, instant answers; and they desire innovative and modern products.

For Rodrigues and Bidarra (2014), the breakdown of traditional assumptions and educational models has driven educators to explore different learning methods to meet the needs of the "new student", by incorporating new kinds of inputs, media consumption and production practices, global resources, and accommodating the shift towards an environment centered more on the student. If learning is understood as a process where the student has to slowly gain autonomy in the direction and control of his or her evolution, the use of resources should fully match their personal choices. Thus, the evolution of technology as a resource for supporting learning leads to situations where the content and the tools are increasingly indistinguishable; that is, the future of teaching materials will be inseparable from their technological support (García \& López-Pérez, 2012).

The alternative discussed here for learning through stories is an important way of reinforcing students' imaginations and empathy (Wood, 2014). Studies carried out on every-day scenarios have shown that storytelling is a primary method for resolving problems (Jonassen \& Hernandez-Serrano, 2002). According to Lima (2014), transmedia storytelling is a way of presenting subjects in a manner that attracts students, while still including academic content, challenging the notion that education and entertainment are opposite ends of a spectrum. Thus, transmedia storytelling, when used as a educational tool by the teacher, is able to align the Open Educational Resources (OER) with activities that are part of the students' daily activities. OER includes teaching, learning, and research resources that give teachers as well as students the freedom to adapt the content according to the needs of a given context.

Gosciola and Versuti (2012) also class transmedia storytelling as an OER, viewing it as a unique option for telling amplified stories, taking into consideration the high level of interaction between the subjects involved in the communication process. Kress (2003) points out that modern literacy requires the ability to express ideas across a wide range of systems of representation and meaning, as each medium has its own inherent characteristics, its own systems of representation, and strategies for producing and organizing knowledge. Using different media platforms, participants explore the different and sometimes conflicting methods of representation and they choose the best way of expressing their ideas, since audiences display migratory behavior when deciding which storytelling sequence and platform they will choose (Gosciola, 2011).

Jonassen and Hernandez-Serrano (2002) suggest three ways of supporting the use of stories in learning: first, they can be used as examples of concepts or principles taught with direct instruction; second, they can be used as case study problems to be solved by students; and third, the stories can be used to advise students and help them to solve problems. According to Rodrigues and Bidarra (2014), transmedia projects show that the creation of worlds through stories can be used to fulfil educational goals; they reinforce and backup the content in a rich and fruitful way for students. The creation of a transmedia learning environment calls for an urgent redefinition of curricular learning, bringing the leaning processes closer to the real contexts in which the students socialize, have fun, and learn informally.

Sharda (2010) reinforces the argument that the potential of working with transmedia storytelling resides in the possibility to connect the educational content with activities that are already present in the daily lives of the students. As such, it is possible to infer that the use of these open resources can help educators to develop strategies that better meet the needs of the students, precisely because they adapt to their context, also taking into account the students' different learning stages, unique characteristics, and interests. For example, Jonassen and Hernandez-Serrano (2002) proposed that, in order to train professionals ready to deal with the complexity of situations in the workplace, it is necessary to tell them stories from the workplace, so that students reflect on the similarities and differences between the situation/problem and the story presented, to find lessons and solve problems.

A different proposal arising from transmedia storytelling is the idea of digital storytelling. For Flottemesch (2013), digital storytelling is a multi-modal approach that brings the ancient art of storytelling to life using technology. Meadows (2003) believes that digital storytelling is the social practice of storytelling using low-cost digital cameras, non-linear design tools, and computers to create multimedia short stories. These are essentially personal stories made for publication on the internet. It is important to realize that the way to incorporate storytelling in the process of teaching and learning is very comprehensive and can be adapted to the reality of each 
location by adapting the specific methodology and media to convey the story.

\subsection{The Effectiveness of Transmedia Storytelling as a Teaching Tool}

Information and communication technologies have increasingly become the model for teaching in the classroom, because they make it possible to turn the classroom into environments where teachers have different resources for students to perform a series of tasks, according to the specific needs that arise form the process (García \& López-Pérez, 2012). As such, the transmedia storytelling method is gaining ground. Humans seem to have an innate ability and willingness to organize and represent their experiences in the form of stories (Jonassen \& Hernandez-Serrano, 2002). For Fitzgibbon and Wilhelm (1998), stories help communicate literary and cultural heritage, while also helping students to better develop a sense of rhetorical structure. The advantages most often cited in literature are affective advantages, given that the story interests students, lowers affective filters, and allows learning to take place more naturally as part of an interactive communication. If new ideas and concepts are taught within the context of a story, students are more likely to understand, since they are dealing with familiar details while at the same time being introduced to new concepts.

According to Kalogeras (2013a, 2013b), transmedia storytelling that is entertaining and educational is a critical-creative teaching method of active research and creative action that creates memories, empowers students, and adds value to the community. This transformative learning helps student discover the meaning of the text, and to re-create, reflect, refract, reshape, and retain information. Menkhoff and Bengtsson (2012) argue that information and communication technologies (ICT) used by Generation Y students in their daily life could significantly enrich the experience of said students and produce valuable learning results based on combined learning.

To this end, using mobile learning devices brings excitement to the classroom and helps educate students. They are also devices of daily communication with which the students are familiar (Menkhoff \& Bengtsson, 2012). However, attention should also be paid to the quality of the story. In a study carried out by Sangalang et al. (2013), quality was the most important element in the narrative, because the ease with which the events are constructed contribute to the fluidity and understanding of the world in the story. Thus, the audience is able to synthesize elements of the story from between the different media platforms. In addition, for Raybourn (2014), the capacity to track the interaction, feedback, and content generated by the user through mining social media activities and data is essential for designing transmedia campaigns and measuring the level of learning.

In order to verify the effectiveness of the use of transmedia storytelling in the teaching and learning process, empirical studies found in the literature will be addressed, considering some of the their main theoretical-practical findings:

The study by Sangalang et al. (2013) researched the involvement of the audience with an interactive game designed as part of a greater transmedia storytelling effort, created with a narrative structure and with the purpose of encouraging the consumption of milk. In addition, the factors that influences involvement were studied: fun and frustration; it was shown that understanding the narrative is linked to the feeling of involvement and to the experiences of the participants (transportation). The processing of the audience takes place over two distinct levels: the understanding of the events in the story within a storyline and the synthesizing of narrative threads within the larger narrative world. Although it was an exploratory study, it was an attempt to conceptualize and assess involvement with a story in educational entertainment transmedia storytelling campaigns.

Menkhoff and Bengtsson (2012) integrated mobile learning devices, such as mobile phones, photo sharing sites, wikis, podcasts, and walking tours with students as educational tools in an undergraduate degree in Chinese entrepreneurship. The experiences suggest that the integrated online learning resources are key to facilitate the sharing of information and knowledge between colleagues. The study suggests that a teaching method which puts an emphasis of mobile learning technologies within a context of combined learning, which includes mini lectures, presentations by students, guided tours, and field trips with an educational approach clearly helps to promote learning.

The study carried out by Wood (2014) dealt with the imagination and, especially, the theory of reader response, in learning through storytelling for nursing students. Historical imagination, based on a story of a nurse from the past, provided support when describing the responses of readers (post-graduate nursing students), illustrating how learning through storytelling can be achieved in practice. This analysis showed that the use of historical stories engages students' imaginations, causing them to have discussions, question their assumptions, and translate the past into the present. As such, the theory of reader response offers a valuable base for learning 
through storytelling.

Niemi et al. (2014) showed how digital storytelling can create virtual learning environments when used for teaching the skills that students will need in their future professional lives. As such, students have a central role in the creation and construction of knowledge through different kinds of material tools, acting as producers of content as well as consumers. For Niemi et al. (2014), when planning and creating digital stories, students become conscious of their own knowledge and experiences, and are able to reflect on them and share them. Similarly, the work of Flottemesch (2013), used digital storytelling as a teaching tool to improve the learning outcomes of students, providing students with an opportunity to be involved in their learning, since the ability to customize stories with images, personal narration, video, animation, music and artifacts is conducive to a deeper level of understanding and meaning.

Also Tan, Lee and Hung (2014) implemented digital storytelling through the use of "edutainment" in a fifth grade science class. The students had to create a story that communicated a scientific concept embedded within the narrative structure in which characters had to experience the effects of the concept. Thus, the quality of the story was measured by the students' level of understanding of the scientific concept. This methodology proved to be feasible, but there is a need to study it in greater depth. The difference was the construction of stories containing the elements of a story together with information on the subject, encouraging students to reflect, interpret, and learn the data to create the story.

The study carried out by Agosto (2013) sought to examine impressions of the performance of oral storytelling in school children by looking at responses from their drawings, writing, and responses, and analyzing the types of educational and social/emotional benefits that children may gain by experiencing oral storytelling. The benefits identified include five types of educational benefits: critical thinking skills, creativity, active participation/ engagement in learning, literacy skills, and narrative thinking skills. Two kinds of social/emotional benefits were also identified: self-exploration and interpersonal skills. Despite this potential, according Pietschmann, Völkel and Ohler (2014), transmedia content has limitations for children: its complex narrative structure cannot simply be adapted to make it suitable for children. From the point of view of developmental psychology, younger children lack adults'ability to use, understand, and participate in transmedia franchises.

\subsection{Transmedia Storytelling Teaching Results to Students}

Use either SI (MKS) or CGS as primary units. (SI units are encouraged.) English units may be used as secondary units (in parenthe Society is changing from an era of information to an era of engagement in which storytelling is always present (Kalogeras, 2013a, 2013b). For Taylor and Parsons (2011), student engagement has become both a strategic learning process and a result of accountability itself. According to Massarolo and Mesquita (2013), in the school environment, the migration of young students through spaces characterized by mobility, interactivity, and collaboration reinforces the emergence of a new culture based on the participation of students in the creative processes of the stories. As such, the production of fan fiction, which is created collaboratively in the form of texts or films and derived from literary works, TV series, movies, comics, video games, and other media franchises, can be considered as an unauthorized expansion of the official text in different directions.

For these reasons, transmedia learning allows sustained learning experiences that result in measurable change in behaviour, which can be physical and explicit, intellectual, related to attitude, or a combination of these forms. However, achieving learning goals through transmedia learning requires systematic thinking and planning (Raybourn, 2014). In the analysis of the literature on common strategies to improve student engagement in learning carried out by Taylor and Parsons (2011), a standard practice has been recommended and repeated, summarized in the following categories: interaction; exploration; relevance; multimedia; instruction and assessment for learning, which calls for teachers to use formative assessment practices to monitor student success and engage in regular conversations with students. According to research by the authors, it is necessary to change the way how teaching is done what is taught, to engage students, adopting a constructivist educational model that requires respectful relationships and safe learning environments, especially with regards to the teacher-student relationship, which should change from expert-disciple to collaborative learning.

Taylor and Parsons (2011) analyzed the types of student engagement, which include academic, cognitive, intellectual, institutional, emotional, behavioral, social, and psychological engagement. The authors concluded that the following criteria characterize engagement: 1) relevant, real, and intentionally interdisciplinary learning (sometimes moving from classroom learning to the community); 2) technology: rich learning environments, not 
just computers, but all kinds of technology, including scientific equipment and various forms of portable communication technology; 3) positive learning environments, challenging and open, also called transparent learning environments that encourage risk-taking and guide students toward co-articulate high expectations; and 4) cooperation with respect, since the relationship between students and teachers also contributes to the engagement.

Efforts to engage students are present in academic research, for example, the study carried out by Tan, Lee and Hung (2014) proposed that students create an edutainment story where it was necessary to understand a given scientific concept; construct a coherent story with problematic situations plausible for the scenario and characters and, at the same time, prepare a situation in which the scientific concept could significantly contribute to solving the problem without seeming too obvious. In many ways, it was designed as an exercise to provoke the students, engage them, and demonstrate their competence in creating stories and applying scientific concepts.

According to Raybourn (2014), transmedia learning takes advantage of several trends of new media, including communication in pairs in social media, the scalability of the massively open online courses (MOOCs), and the design of transmedia narratives used for entertainment, advertising, and by commercial games industries to support engagement with the public. As in the study by Tomkins (2009), in which students were asked to develop stories to guide them through the learning stages, completing the exercises on a weekly basis in order to track their progress and to record their journey with the ultimate goal of reaching the stage of transformative learning. Transformative learning, defined by Tomkins (2009), implies a change in behavior resulting from critical reflections and planned actions resulting from a reflective process. In a way, the storytelling technique helps students meet this challenge, as it provides support for them to build their own meaning derived from the knowledge that they are acquiring, equipping them with a process that provides a model for reflective learning.

Several transmedia elements can be used when designing experiences that create engagement and transform students into active participants in the learning process (Rodrigues \& Bidarra, 2014). Promoting engagement involves motivational qualities, including positive emotional experiences, such as fun; aspirations and inspirations or the enthusiasm of the students; and a commitment or ability to persist with a learning task. Technology is a tool that motivates students and provides scenarios in which they can make their own contributions (Niemi et al., 2014). Rodrigues and Bidarra (2014) call this active participation of students and educators "connected learning", which addresses the challenges of the disconnect between formal education and the social contexts of the students, as well as the need to strengthen civic participation.

\section{Discussion and Analysis}

Many of the research works on transmedia storytelling involve case studies; exploratory studies reporting and teaching experiences and attempts at incorporating elements of transmedia storytelling. It is noted that although the storytelling technique is old, especially oral storytelling, the use of transmedia storytelling is new. However, there is need for further studies and experiences related to the teaching and learning process involving transmedia storytelling, especially considering the constant renewal of information and communication technologies that affect the culture, human behavior, and therefore the ways of teaching the $\mathrm{Y}$ and $\mathrm{Z}$ generations in schools, universities, and other educational institutions.

One issue to be reflected upon is that many studies found in the literature deal with storytelling or the implementation of various media platforms, that is, there is some difficulty in the implementation of a methodology based on stories that are told in parts, fragmented but complementary, as with the use of different media platforms. It is observed certain dissonance in the application of transmedia storytelling learning, studies focus or transmedia literacy or the use of narratives. Similarly, there are no comparative studies of this methodology with children, teenage, and adult audiences; does the use of stories in the classroom have the same effect in children and university students? Efforts to adopt transmedia storytelling methods seem to bear most fruit with younger audiences. Studies involving university students focus on the use of digital media in understanding the proposed content without having a story permeating these different media forms; that is, they focus on the use of technological communication devices without actively developing stories. As such, the concept of transmedia storytelling itself is used erroneously. Grandio-Perez (2016) describes a scenario in which transmedia literacy is scarce and mainly focused on instrumental and technological aspects.

It happens to the study of Niemi et al. (2014) and Flottemesch (2013) that explored the attributes of the digital medium as image, personal narration, video, animation and music to create digital narratives; also, Tan, Lee, and 
Hung (2014) implemented the digital storytelling through edutainment approach. In add the study Menkhoff and Bengtsson (2012) focused only on the use of transmedia and not in the narrative. It is important to highlight that the mere story exposition in different media does not guarantee a transmedia character, which should have its combined and integrated use, not simply transposed (Jenkins, 2009). Similarly, not only the introduction of narratives in teaching learning process even with the support of digital formats, such as in studies of Sharda (2010), Meadows (2003) and Flottemesch (2013) are correct examples of transmedia storytelling methodology.

A relevant issue is that studies in question are specific, compartmentalized, and there is no experience of the use of stories in the classroom. Is it the case that this proposal remains equally effective over time? It is also noted that the use of stories can be combined with other methods such as the problem solving and case studies, bringing together people's ability to identify with and interpret stories, and understand problems based on narratives. This has been seen in the study by Jonassen and Hernandez-Serrano (2002) suggest that the use of stories as examples of concepts, case problems and how advice sources in learning and Wood (2014) that uses the narrative as a teaching case. Although these studies neglect of the characteristics of transmedia storytelling, as evidence only the narratives use, this question proved to be very positive for the desired results.

Technology, information, multitasking, content, connectivity, interactivity, and collaboration are keywords that represent part of a narrative storytelling campaign and which need to be present in the classroom to improve the quality of the teaching and learning process and to engage the teenagers of today. Learning environments mediated by technology have become more interactive, synchronous and flexible, able to connect different digital resources and tools for knowledge creation (Niemi et al., 2014). It is important to consider that the essence of transmedia storytelling is how all the pieces fit together to form a whole that is greater than the sum of its parts.

\section{Final Considerations}

The study achieved its aim of verifying the effectiveness of transmedia storytelling in engaging teenagers in the teaching-learning process. The literature shows that the use of transmedia storytelling has generated very positive results for learning and student engagement in the proposed theme, adopting a teaching method where teachers provide students with various resources to carry out a task, disseminating knowledge, practical skills, and methods for co-learning. In the end, knowledge has to include creativity, innovation, and imagination (Kalogeras, 2013a, 2013b).

The most important factor is that students must have the ability to learn throughout their lives, and that education should provide the skills and mental tools to enable them to do so. Students must have the ability to ask questions. They must be able to not only work independently, but also collaborate with others. Life is increasingly intertwined with technology; learning environments are constantly changing and information and communication technologies offer many new learning opportunities (Niemi et al., 2014). In addition, if education is a way to "transform the soul," and even if not, stories let souls speak and stories can transform souls. People should tell their stories because they reinforce who they are (Kalogeras, 2013a, 2013b).

Further research involving transmedia storytelling experiments in the classroom with different age groups of students and using different disciplines and content will be important to determine whether the effectiveness of this methodology will be maintained, altered, or enhanced. Grandio-Perez (2016) states that, despite the growing literature available on transmedia narratives, one can see the lack of specific literature on transmedia training. In this sense, it would be beneficial to consolidate transmedia literacy in the field of research and the creation of teaching materials to facilitate the teaching of this methodology for teachers. Curricular reform to be a contemporary needs to bring reality into the classroom and allows knowledge to be built together and therefore the use of stories in conjunction with information and communication technologies needs to gain more prominence.

\section{References}

Agosto, D. E. (2013). If I Had Three Wishes: The Educational and Social/Emotional Benefits of Oral Storytelling. Storytelling, Self, Society, 9, 53-76. http://dx.doi.org/10.13110/storselfsoci.9.1.0053

Blumenthal, H., \& Xu, Y. (2012). The Ghost Club Storyscape: Designing for Transmedia Storytelling. IEEE Transactions on Consumer Electronics, 58, 190-196. http://dx.doi.org/10.1109/TCE.2012.6227412

Ceretta, S. B., \& Froemming, L. M. (2011). Geração Z: Compreendendo os Hábitos de Consumo da Geração Emergente. Revista Eletrônica do Mestrado em Administração da Universidade Potiguar, 3, 15-24. https://repositorio.unp.br/index.php/raunp/article/view/70/91 
Fitzgibbon, H. B., \& Wilhelm, K. H. (1998). Storytelling in ESLEFL Classrooms. TESL Reporter, 31, 21-31. https://ojs.lib.byu.edu/spc/index.php/TESL/article/view/3637/3411

Flottemesch, K. (2013). Learning through Narratives: The Impact of Digital Storytelling on Intergenerational Relationships. Academy of Educational Leadership Journal, 17, 53-60.

http://www.alliedacademies.org/academy-of-educational-leadership-journal/volume-issue.php?volume=Volume $\% 2017, \%$ 20Issue\%203\&\&year=2013\&\&journal=aelj

Gambarato, R. R. (2013). Transmedia Project Design: Theoretical and Analytical Considerations. Baltic Screen Media Review, 1, 80-100. http://dx.doi.org/10.1515/bsmr-2015-0006

García, I., \& López-Pérez, C. (2012). La Función de los Recursos de AprendizajeenlaUniversidad. In A. Okada (Ed.), Open Educational Resources and Social Networks:Colearning and Professional Development. London: Scholio Educational Research \& Publishing. http://oro.open.ac.uk/39236/1/OER-completo-final-05-07.pdf

Gosciola, V. (2011). Narrativa Transmídia: A Presença de Sistemas de Narrativas Integradas e Complementares na Comunicação e na Educação. Quaestio, Sorocaba, SP, 13, 117-126.

http://periodicos.uniso.br/ojs/index.php?journal=quaestio\&page=article\&op=view\&path\%5B\%5D=692\&path\%5B $\% 5 \mathrm{D}=7$ $\underline{16}$

Gosciola, V., \& Versuti, A. (2012). Narrativa Transmídia e sua Potencialidade na Educação Aberta. In A. Okada (Ed.), Open Educational Resources and Social Networks: Colearning and Professional Development. London: Scholio Educational Research \& Publishing. http://oro.open.ac.uk/39236/1/OER-completo-final-05-07.pdf

Grandio-Perez, M. M. (2016). El transmedia en la ensenanzauniversitaria. Analisis de lasasignaturas de educacionmediatica en Espana (2012-2013). Palabra Clave, 19, 85-104. http://dx.doi.org/10.5294/pacla.2016.19.1.4

Ibope Media (2015). Gerações Y e Z: Juventude Digital, Geração Y (20 a 29 anos) Geração Z (12 a 19 anos), Target Group Index BrY11w1+w2 (Ago09-Jul10). http://www4.ibope.com.br/download/geracoes\%20_y_e_z_divulgacao.pdf

Jenkins, H. (2009). Cultura da Convergência. São Paulo: Aleph.

Jenkins, H. (2007). Transmedia Storytelling. Confessions of an Aca-fan. The Oficial Weblog of Henry Jenkins. http://www.henryjenkins.org/2007/03/transmedia_storytelling_101.html

Jenkins, H., Purushotma, R., Weigel, M., Clinton, K., \& Robison, A. J. (2009). Confronting the Challenges of Participatory Culture: Media Education for the 21st Century. Cambridge, MA: The MIT Press.

Jonassen, D. H., \& Hernandez-Serrano, J. (2002). Case-Based Reasoning and Instructional Design Using Stories to Support Problem Solving. Educational Technology Research and Development, 50, 65-77. http://dx.doi.org/10.1007/BF02504994

Kalogeras, S. (2013a). Media-Education Convergence: Applying Ttransmedia Storytelling Edutainment in E-Learning Environments. International Journal of Information and Communication Technology Education, 9, 1-11.

http://www.palgraveconnect.com/pc/doifinder/10.1057/9781138388377.0001M http://dx.doi.org/10.4018/jicte.2013040101

Kalogeras, S. (2013b). Storytelling: An Ancient Human Technology and Critical-Creative Pedagogy for Transformative Learning, International Journal of Information and Communication Technology Education, 9, 113-122. http://dx.doi.org/10.4018/ijicte.2013100108

Kinder, M. (1991). Playing with Power in Movies, Television, and Video Games: From Muppet Babies to Teenage Mutant Ninja Turtles. Berkeley, CA: University of California Press.

Kress, G. (2003). Literacy in the New Media Age. New York: Routledge.

Lima, E. F. O. (2014). Recursos Educacionais Abertos: Ensino através de Conteúdos Transmidiáticos. Anais do XVI Congresso de Ciências da Comunicação na Região Nordeste, João Pessoa, 15-17 May 2014, 1-11. http://portalintercom.org.br/anais/nordeste2014/trabalhos dt.htm

Massarolo, J. C., \& Mesquita, D. (2013). Narrativa Transmídia e a Educação: Panorama e Perspectivas. Revista Ensino Superior Unicamp, 34-42. https://www.revistaensinosuperior.gr.unicamp.br/artigos/narrativa-transmidia-e-a-educacao-panorama-e-perspectivas

Meadows, D. (2003). Digital Storytelling: Research-Based Practice in New Media. Visual Communication, 2, 189-193. http://vcj.sagepub.com/content/2/2/189.extract http://dx.doi.org/10.1177/1470357203002002004

Menkhoff, T., \& Bengtsson, M. L. (2012). Engaging Students in Higher Education through Mobile Learning: Lessons Learnt in a Chinese Entrepreneurship Course. Educational Research for Policy and Practice, 11, 225-242.

https://www.learntechlib.org/p/71973/ http://dx.doi.org/10.1007/s10671-011-9123-8

Niemi, H., Harju, V., Vivitsou, M., Viitanen, K., Multisilta, J., \& Kuokkanen, A. (2014). Digital Storytelling for 21st-Century Skills in Virtual Learning Environments. Creative Education, 5, 657-671. http://dx.doi.org/10.4236/ce.2014.59078 
Padgett, D., \& Allen, D. (1997). Communicating Experiences: A Narrative Approach to Creating Service Brand Image. Journal of Advertising, 26, 49-62.

http://www.jstor.org/stable/4189050?origin=JSTOR-pdf\&seq=1\#page_scan_tab_contents http://dx.doi.org/10.1080/00913367.1997.10673535

Pietschmann, D., Völkel, S., \& Ohler, P. (2014). Limitations of Transmedia Storytelling for Children : A Cognitive Developmental Analysis. International Journal of Communication, 8, 2259-2282. http://ijoc.org/index.php/ijoc/article/viewFile/2612/1205

Raybourn, E. M. (2014). A New Paradigm for Serious Games: Transmedia Learning for More Effective Training and Education. Journal of Computational Science, 5, 471-481. http://dx.doi.org/10.1016/j.jocs.2013.08.005

Rodrigues, P., \& Bidarra, J. (2014). Transmedia Storytelling and the Creation of a Converging Space of Educational Practices. International Journal of Engineering and Technology (iJET), 9, 42-48.

Sánchez, C. C. (2013). Narrativas Transmedia Nativas: Ventajas, Elementos de laPlanificación de un Proyecto Audiovisual Transmedia y Estudio de Caso. Historia y Comunicación Social, 18, 561-574.

Sangalang, A., Quintero Johnson, J. M., \& Ciancio, K. E. (2013). Exploring Audience Involvement with an Interactive Narrative: Implications for Incorporating Transmedia Storytelling into Entertainment-Education Campaigns. Critical Arts: South-North Cultural and Media Studies, 27, 127-146. http://ccms.ukzn.ac.za/publications/critical-arts.aspx http://dx.doi.org/10.1080/02560046.2013.766977

Scolari, C. A. (2009). Transmedia Storytelling: Implicit Consumers, Narrative Worlds, and Branding in Contemporary Media Production. International Journal of Communication, 3, 586-606. http://ijoc.org/index.php/ijoc/article/view/477/336

Sharda, N. (2010). Using Storytelling as the Pedagogical Model for Web-Based Learning in Communities of Practice. In N. Karacapilidis (Ed.), Web-Based Learning Solutions for Communities of Practice: Developing Virtual Environments for Social and Pedagogical Advancement (pp. 67-82). Hershey, PA: Information Science Reference. http://vuir.vu.edu.au/8402/ http://dx.doi.org/10.4018/978-1-60566-711-9.ch006

Tan, M., Lee, S.-S., \& Hung, D. W. L. (2014). Digital Storytelling and the Nature of Knowledge. Journal Education and Information Technologies, 19, 623-635. http://dx.doi.org/10.1007/s10639-013-9280-x

Tapscott, D. (2010). A Hora da Geração Digital: Como os Jovens que Cresceram Usando a Internet Estão Mudando Tudo, das Empresas aos Governos. Rio de Janeiro: Agir Negócios.

Taylor, L., \& Parsons, J. (2011). Improving Student Engagement. Current Issues in Education, 14, 1-32. http://cie.asu.edu/ojs/index.php/cieatasu/article/viewFile/745/162

Tomkins, A. (2009). "It Was a Great Day When...”: An Exploratory Case Study of Reflective Learning through Storytelling. Journal of Hospitality, Leisure, Sport and Tourism Education, 8, 123-131.

Wood, P. J. (2014). Historical Imagination, Narrative Learning and Nursing Practice: Graduate Nursing Students’ ReaderResponses to a Nurse's Storytelling from the Past. Nurse Education in Practice, 14, 473-478.

http://dx.doi.org/10.1016/j.nepr.2014.05.001 